\title{
Chile-América, 1974-1983: Una revista del exilio chileno ${ }^{1}$
}

\author{
Danny Gonzalo Monsálvez Araneda ${ }^{2}$ \\ Nicollet Andrea Gómez Rojas ${ }^{3}$
}

Resumen: El siguiente artículo propone estudiar la relación entre la revista ChileAmérica con el exilio político chileno. Se busca aportar a la identificación de nuevos actores políticos-culturales a partir del proceso de creación de revistas creadas en el exilio como espacios de discusión, de reencuentro intelectual y político. Para este objetivo se analizan los propósitos y objetivos de la revista en estudio; así como su contenido a través de una sistematización en ejes temáticos; y su proceso de difusión.

Palabras clave: Chile - Dictadura militar Revista Chile-América - Exilio - Intelectuales

\begin{abstract}
: the following article proposes to study the link between the magazine ChileAmérica and the Chilean political exile. The aim is to contribute to the identification of new political-cultural factors, based on the process of creating magazines created in the exile as spaces for discussion, intellectual and political reunion. For this purpose, the purposes and objectives of the journal under study are analysed, as well as its content through a systematization in topic axes, and its dissemination process.
\end{abstract}

Keywords: Chile - Military dictatorship Chile-America Magazine - Exile - Intellectuals

\section{Introducción}

Desde principios del siglo XX, las revistas en América Latina se constituyeron en importantes espacios de encuentro para políticos e intelectuales, siendo las páginas de estas publicaciones una muestra de los debates en torno a ideas y proyectos de sociedad. De esta manera, a fines

\footnotetext{
${ }^{1}$ Trabajo recibido el 10/10/2017. Aceptado el 15/12/2017.

2 Profesor de Historia y Geografía y Magíster en Historia por la Universidad de Concepción, Chile. Doctor en Historia por la Pontificia Universidad Católica de Valparaíso, Chile. Académico en el Departamento de Historia de la Universidad de Concepción. Contacto: monsalvez@udec.cl

${ }^{3}$ Licenciada y Maestranda en Historia por la Universidad de Concepción, Chile. Contacto: ngomez@udecl.cl
} 
de la década de 1950 uno de los grandes temas de discusión que se formularon en los núcleos intelectuales de izquierda fue el debate entre reforma o revolución, constituyéndose como uno de los ejes principales, no solo para el campo intelectual sino también para la organización política y el resto de la sociedad.

Este nuevo alcance que tomó el boom editorial marcó las décadas de 1960 y 1970, caracterizándose por la renovación en las lecturas del marxismo, el apoyo y solidaridad a la Revolución Cubana y el desarrollo de nuevas estrategias para la creación de un nuevo proyecto de sociedad (Gilman, 2012; Alburquerque, 2011).

Para el caso chileno, el martes 11 de septiembre de 1973 ponía fin a un periodo en el cual los intelectuales, particularmente de izquierda, habían asumido un rol clave a la hora de los debates y controversias sobre los proyectos de transformación social para Chile. Arrate y Rojas lo definirían como el alejamiento de las ideas y las prácticas que constituyeron la cultura de izquierda (Arrate y Rojas, 2003, p. 169). En ese sentido, la intervención militar de 1973 no solo fue un golpe a la democracia y a la institucionalidad política existente en Chile, sino que representó para muchos la destrucción del proceso de transformaciones que había puesto en marcha el gobierno de la Unidad Popular.

La dictadura militar chilena instauró una nueva realidad social que significó la eliminación del discurso de la izquierda nacional a partir de la destrucción e intervención de los espacios donde se ejercieron las prácticas políticas y debates intelectuales antes del 11 de septiembre de 1973. Además, el régimen dictatorial impulsó una sistemática violación de los derechos humanos. En este contexto de intervención y desarticulación de los espacios de sociabilidad política, un gran número de políticos e intelectuales se vieron obligados a abandonar el país. A partir de aquella medida comenzó a gestarse todo un proceso de ayuda y solidaridad internacional, no solo de chilenos que estaban en el extranjero sino que también de algunos países que acogieron y dieron protección a quienes eran expulsados de Chile.

En las diferentes realidades que vivieron los intelectuales y políticos exiliados, empezó a vislumbrarse la creación de algunas publicaciones como espacios de encuentro y reunión, con el fin de articular pequeños núcleos opositores en torno a estas publicaciones, donde a través de editoriales, documentos, artículos y opiniones se desarrolló progresivamente un diálogo permanente con la condición de exiliados y con la creación de un proyecto político alternativo al impuesto por la dictadura. 
De esta forma, Chile-América nació como una necesidad de buscar una vía o mecanismo para expresar públicamente lo que estaba pasando en Chile y Latinoamérica. Por ello, el carácter de la revista no era meramente informativo, sino crítico de los regímenes dictatoriales, donde se buscaba influir a través del discurso en la realidad en la cual estaban inmersos.

En el texto aquí presente nos aproximamos a la revista Chile-América a partir de una exploración que indaga en: su creación, contenido, objetivo y difusión. Asimismo, se valora su importancia al convertirse en un espacio de reencuentro intelectual y político, que habría buscado superar las barreras geográficas y las diferencias políticas e ideológicas que se dieron previo al golpe cívico-militar. Esto se lograría por medio, de la creación de redes de discusión y espacios de encuentro intelectual y político, las que habrían ayudado a generar un proyecto alternativo a la dictadura.

\section{Contexto dictatorial y exilio chileno: fundación de Chile-América}

Si bien en la historia de Chile se habían vivido momentos de tensión y quiebres institucionales que estuvieron marcados por la violencia y represión, lo ocurrido tras el golpe de Estado en Chile no tuvo precedente alguno. A partir de aquella coyuntura la dictadura encabezada por Augusto Pinochet impulsó desde el Estado una represión sistemática contra los opositores, en la que se legitimó y legalizó la violencia política como mecanismo para imponer un determinado orden social (Dorat y Weibel, 2012; Salazar, 2011 y 2012).

Los días y meses posteriores al golpe de Estado estuvieron marcados por la desarticulación de los espacios de sociabilidad, disolución y «receso» de los partidos políticos y la actividad sindical ligada históricamente a la izquierda, a lo cual se sumó la censura, la relegación, el exilio y la tortura.

Los Comandantes en Jefe ${ }^{4}$ formaron una Junta de Gobierno que asumió el Poder Ejecutivo y, al mismo tiempo, anuló al Legislativo y «mediante los Decretos Leyes $\mathrm{N}^{\circ} 3$ y $\mathrm{N}^{\circ} 5$ declaró el estado de sitio con el carácter de 'estado o tiempo de guerra', lo que implicaba el funciona-

\footnotetext{
${ }^{4}$ General Augusto Pinochet Ugarte, General del Aire Gustavo Leigh Guzmán y el Almirante José Toribio Merino, junto con el General de Carabineros, César Mendoza Durán.
} 
miento de tribunales militares en tiempo de guerra y la aplicación de la correspondiente penalidad agravada» (Brinkmann, 1999, p. 21). Estas medidas de guerra estaban basadas en los postulados de la Doctrina de Seguridad Nacional, es decir, buscaban la derrota de los enemigos ideológicos. ${ }^{5} \mathrm{La}$ «guerra contra el enemigo interno» era impuesta por los militares como argumento para justificar y prolongar de manera definitiva el régimen autoritario.

El Congreso Nacional y el Tribunal Constitucional fueron disueltos, argumentando «la necesidad de contar con la mayor expedición en el cumplimiento de los postulados que la Junta se ha propuesto». ${ }^{6} \mathrm{El}$ Poder Judicial no vio cercenadas sus funciones debido a que la mayoría de sus miembros habían mostrado una actitud amistosa, incluso obediente al régimen recién instaurado. El «cuerpo legal» en el que se apoyó la Junta Militar se fundamentó en decretos leyes. La primera que podemos identificar es el Decreto Ley 81, publicado el 6 de noviembre de 1973, en el cual se establecía que el Gobierno podía disponer de: «la expulsión o el abandono del país de determinadas personas, extranjeros o nacionales». Además establecía las personas que no podían reingresar al país sin el permiso del Ministerio del Interior:

a) las que salieron del país por vía de asilo; b) las que abandonaron el país irregularmente; c) las que salieron expulsadas por el Gobierno; d) las que estaban cumpliendo penas por extrañamiento; e) y (...) las que fueron llamadas a presentarse ante la autoridad y que encontrándose en ese momento en el extranjero, no se presentaron (Rebolledo, 2006, p.19)

El mismo artículo se refería a que en el caso que se ingresara clandestinamente a Chile se aplicaría la pena de muerte. El segundo Decreto Ley que podemos identificar fue el $\mathrm{N}^{\circ} 604$, publicado el 9 de agosto de 1974, que en sus artículos agregaba nuevas razones de expulsión y otorgaba al Ministerio del Interior la competencia de autorizar el ingreso al país:

\footnotetext{
${ }^{5}$ La definición de enemigo por parte de las Fuerzas Armadas resulta ser amplia y algo ambigua, no sólo los marxistas y comunistas son enemigos, sino que también cualquier persona o grupo que cuestionara el orden imperante. Por ello, se atacó sin mayores filtros a la población. Esto no sólo servía para infundir el miedo como disciplinamiento sino que también como una forma de evitar futuros alzamientos.
}

${ }^{6}$ Decreto Ley $\mathrm{N}^{\circ} 27,24$ de septiembre de 1973. 
Artículo $1^{\circ}$ - Se prohíbe el ingreso al territorio nacional de las personas, nacionales o extranjeras, que propaguen o fomenten, de palabra o por escrito o por cualquier otro medio, doctrinas que tiendan a destruir o alterar por la violencia el orden social del país o su sistema de Gobierno; los que estén sindicados o tengan reputación de ser agitadores o activistas de tales doctrinas y, en general, los que ejecuten hechos que las leyes chilenas califiquen de delito contra la seguridad exterior, la soberanía nacional, la seguridad interior o el orden público del país y los que realicen actos contrarios a los intereses de Chile, o a juicio del Gobierno constituyan un peligro para el Estado ${ }^{7}$

Un gran número de chilenos y chilenas partieron al exilio, pero hasta la fecha no se conocen las cifras exactas de la migración causada por la dictadura chilena. Algunos autores basados en información de distintas organizaciones estiman que entre $« 500.000$ y 1.000 .000 de personas dejaron el país entre 1973 y 1989» (García, 2013, p. 83). Otras cifras son más moderadas, según las cuales se calcula que «habrían salido del país 408.000 personas, siendo sus principales destinos Argentina $(50,78 \%)$, Estados Unidos $(7,8 \%)$, Venezuela $(6,18 \%)$, Canadá $(3,85 \%)$, Francia $(3,68 \%)$, Italia $(2,38 \%)$, Suecia $(2,38 \%)$ y Australia $(2,21 \%) »$ (Norambuena, 2000, p. 178). Lo que sí se sabe es que el exilio afectó especialmente a un sector importante de la sociedad, identificados con un proyecto político, que compartían una identidad política y que eran militantes o simpatizantes de izquierda, así como opositores a la dictadura (García, 2013, p. 84).

A partir de aquel momento, el exilio chileno estuvo marcado por la salida de un gran número de artistas, intelectuales, profesionales y universitarios, además de una gran cantidad de políticos. Estos hombres y mujeres darían vida con el tiempo a diversas formas de oposición y resistencia contra la dictadura. Dentro de este contexto histórico nació en Italia la Revista Chile-América.

\section{Chile-América: una revista en el exilio político chileno}

Creada en 1974, su primera publicación vio la luz en septiembre, a un año del golpe militar, su sede oficial fue Roma, lugar donde se editó mensualmente. Chile-América fue una revista de análisis político y pe-

\footnotetext{
${ }^{7}$ Ley $\mathrm{N}^{\circ} 604$, publicado el 9 de agosto de 1974. El decreto se encuentra completo en: http://www.leychile.cl/Navegar?idNorma $=6225$. El destacado es nuestro.
} 
riodístico, fundada y dirigida por intelectuales y políticos chilenos vinculados al Partido Demócrata Cristiano (PDC), a la Izquierda Cristiana (IC) y al depuesto gobierno de la Unidad Popular (UP). La labor de publicación de esta revista, producto de un proyecto concebido por cuatro políticos, constituyó un caldo de cultivo del pensamiento de oposición al régimen dictatorial, así como un paso decisivo en la tarea de reorganización política y cultural en el extranjero. Cabe recordar que la matriz de la IC (fundada en 1971) fue la Democracia Cristiana. Hacia 1971, este último partido experimentó una crisis interna. Un sector de la colectividad, específicamente aquellos izquierdistas liderados por el dirigente Bosco Parra expresaron que ningún organismo del partido debería establecer alianzas con colectividades de derecha. Como su propuesta no tuvo cabida en la DC, éste decidió renunciar junto a otros dirigentes. Los argumentos para abandonar el partido fueron «la permanente contradicción entre el discurso izquierdista de la DC y su práctica derechista». En segundo lugar, sostuvieron que aquella contradicción «cuestionaba la credibilidad del discurso y dejaba al descubierto el verdadero móvil de la acción de la colectividad». Finalmente, plantearon que el partido, «como consecuencia de lo anterior, había dejado de ser el órgano idóneo para llevar a cabo los ideales del socialismo comunitario». Junto con Bosco Parra se fueron seis parlamentarios del partido: Luis Maira, Pedro Videla, Pedro Urra, Alberto Jaramillo, Fernando Buzeta y Jaime Concha. Posteriormente se sumaron Pedro Felipe Ramírez y Osvaldo Giannini (Corvalán, 2017, pp. 150-151). Pero no fue todo, a los parlamentarios se sumaron dirigentes del partido a nivel nacional, el presidente de la Juventud Demócrata Cristiana, Luis Badilla, y un número significativo de la juventud de la colectividad.

Días más tarde, la IC expresó su compromiso con la idea de participar en la construcción del socialismo en Chile desde una perspectiva cristiana. Fue así como en agosto de 1971 el nuevo conglomerado proclamó su adhesión al Programa de la UP. De ahí, el ingreso a la coalición de gobierno era cuestión de horas. De hecho, fue el propio Salvador Allende quien ofreció a la IC el ingreso al gobierno. Este proceso ocurrido al interior de la DC y como consecuencia en la UP significó, como señala Corvalán (2016), que al interior del bloque oficialista confluyeran «tres de las corrientes ideológicas-culturales más importantes del país: el marxismo, el laico racionalista y ahora, el cristianismo de izquierda» (p.155). En consecuencia, las relaciones y vínculos que se dieron tras el golpe de Estado de 1973 entre sectores de la DC y de la IC no eran 
nuevos, sino que compartían una matriz ideológica cristiana pero se habían distanciado por la dinámica del proceso de la «Vía chilena al socialismo».

Retomando el tema de la Revista, en esta primera etapa su Comité Editor estuvo conformado por Bernardo Leighton Guzmán, Julio Silva Solar, Esteban Tomic y José Antonio Viera Gallo. Su director hasta 1982 fue Julio Silva Solar y su Director Responsable fue Giovanni Spinelli. A este grupo años más tarde se sumaron Benjamín Teplisky y Fernando Bachelet. Así pues, Chile-América nació estableciendo un marcado carácter político a su discurso, rigurosidad y una pluralidad política reflejada en la diversidad ideológica de sus colaboradores.

Sus primeras ediciones contaban con alrededor de veinte páginas, pero ya a finales de 1974 bordeaban las sesenta y a partir de 1975 superaban las ciento cincuenta, llegando en una ocasión a contener doscientas setenta y ocho páginas. Al respecto, Esteban Tomic (2013) recuerda: «En sus nueve años de existencia, Chile-América publicó 7.116 páginas. iUn trabajo inmenso, que equivale a haber escrito dos páginas diarias!» (p. 7).

Con ochenta y nueve números publicados en casi diez años de existencia, Chile-América tuvo como propósito publicar y difundir artículos y críticas en contra del régimen militar de Pinochet. En su declaración de principios podemos leer que se configuraba como un lugar no solo de resistencia, sino también de encuentro, que, aunque de matriz cristiana, buscaba la inclusión de otros sectores políticos. En Posición y Propósitos escribían:

Ante esta situación, nos ha parecido indispensable canalizar la voz de los cristianos que, en diversas tiendas políticas o independientemente, luchan por el restablecimiento de la democracia y la libertad de Chile. El grupo inicial de Chile-América está compuesto por personas que militan en los partidos de la izquierda chilena y personas que perteneciendo a la Democracia Cristiana, condenaron desde el primer momento la intervención militar y la dictadura. Chile-América quiere hacer llegar esta voz unitaria al mayor número de personas, dentro y fuera de Chile, a fin que no se adormezca la conciencia democrática. No queremos ser una voz excluyente. Muy por el contrario, pensamos que este es el momento de sumar el mayor número de fuerzas ${ }^{8}$

\footnotetext{
${ }^{8}$ Chile-América, (septiembre de 1974), (1), p. 4.
} 
En este plano, la revista se configuró como un espacio de integración de quienes otrora habían estado en oposición. Sin embargo, el que la revista no fuera un portavoz oficial de ningún partido político ayudó a que se recibieran contribuciones de distintas tendencias políticas, como aquellas que provinieron del mundo comunista. Otra característica que cabe mencionar es el idioma utilizado. La revista no solo se editó en español, sino que también fue publicada en inglés e italiano, mostrando un interés por alcanzar el público más amplio posible.

La editorial de lanzamiento no explicitó de dónde provenía el nombre de la revista. Sin embargo, en ediciones posteriores se señaló el porqué de su nombre indicando que Chile-América significaba vincular la realidad de Chile a la latinoamericana, debido a que según ellos no se podía entender lo que ocurría en el país chileno «sino a la luz de los acontecimientos que se producen en el conjunto de ellos». ${ }^{9}$

Los responsables de que se publicara la revista durante sus años de circulación fueron Bernardo Leighton, Esteban Tomic, Julio Silva y José Viera Gallo, pero la ayuda monetaria provino de la DC italiana o al menos eso es lo que se ha señalado hasta el momento. Los testimonios en este punto difieren. Tomic (2013) señala que quien prometió ayuda financiera fue el diputado y luego senador por la DC Gilberto Bonalumi, unas 500.000 liras italianas que equivalían a unos mil dólares, pero esta ayuda nunca se materializó (p.4). Sin embargo, Viera Gallo (2013) recuerda en sus memorias que Bonalumi había prometido un aporte de mil dólares de parte del dirigente de DC Amitore Fanfani y que este gesto habría decidido a los chilenos exiliados a llevar a cabo su proyecto. Aunque no sabemos si realmente hubo apoyo monetario de la DC italiana, esto no impidió que la iniciativa política de crear Chile-América se concretara. En esta primera etapa se incorporó el periodista Fernando Murillo, quien había viajado desde Corea del Norte a Roma (Viera Gallo, 2013, p. 215) y quien se desempeñaría como Director del Centro de Estudios y Documentación Chile-América (CH-A).

Otro elemento interesante de mencionar es que, aunque no se sabe de donde provenían los fondos de la revista y si hubo o no ayuda del Partido Demócrata Cristiano italiano, el problema financiero fue una constante en los casi diez años que duró la revista. Al respecto Tomic (2013) señala lo siguiente:

\footnotetext{
${ }^{9}$ Chile-América, (1975), (6-7), p. 8.
} 
El domingo 11 de agosto escribí en mi Diario: «he vuelto a ver a Leighton, Julio Silva y Viera-Gallo. Conversaciones interesantes. Sigue adelante nuestro proyecto del Centro Chile-América, aunque con dificultades financieras, porque los italianos parece que no cuentan con medios para ayudar. Pero saldremos adelante. Esta es una iniciativa muy importante (p. 4)

En más de una ocasión fue inserto un cuadro informativo que señalaba los problemas económicos por los que pasaba Chile-América, por los cuales se tomó la decisión de unir ediciones. Además, siempre se llamaba a los lectores a suscribirse a la revista: como estrategia de difusión, pero al mismo tiempo como medio para solventar las publicaciones:

'Chile-América' encarece que a quienes deseen recibir nuestra revista que deben suscribirse. El valor de suscripción es US\$ 24 (veinticuatro dólares americanos) por 12 números. 'Chile-América' se distribuye sólo mediante suscriptores. Nuestros lectores y amigos deben comprender que la suscripción es indispensable para financiar la revista (...) Les agradecemos lo que uds. puedan hacer para ayudarnos a sostener la revista ${ }^{10}$

En este mismo ámbito, la publicación número 22-23-24, lanzaba la campaña para comprometer 1000 suscriptores:

Mantener en actividad el Centro y continuar la publicación ha sido una tarea de grandes sacrificios y esfuerzos. Sin embargo, los problemas económicos que confrontamos son serios debido a que hasta hoy no tenemos una base de financiamiento estable. Tenemos que agradecer importantes donaciones recibidas de distintos sectores. Pero las perspectivas para 1977 son muy difíciles ${ }^{11}$

En ediciones posteriores podemos ver que tuvo éxito el llamado, pero sin duda desde sus inicios uno de los grandes problemas de ChileAmérica fue el financiamiento. ${ }^{12}$

\footnotetext{
${ }^{10}$ Chile-América, (junio-julio de 1976), (19-20-21), p. 253.

${ }^{11}$ Chile-América, (agosto-septiembre-octubre de 1976), (22-23-24), p. 192.

${ }^{12}$ Según Viera-Gallo (2013) los aportes estables que recibía la revista provenían del aporte de la Iglesia Católica y de las iglesias evangélicas de Holanda, Bélgica, Francia, Alemania e Italia. Además, no habrían recibido ningún sostén financiero de agrupaciones políticas ni de fundaciones ligadas a ellas (p.218).
} 
De aquí podemos desprender otro elemento y es la precariedad económica en el exilio. Según recuerda Viera Gallo (2013), salvo Fernando Murillo que se dedicaba a tiempo completo a su trabajo periodístico, ninguno de los otros miembros de la revista recibía ingresos por ese trabajo. Cabe señalar que la revista Chile-América tenía como objetivo principal incentivar la reflexión política de la DC y de la ex UP, aunque esto no significaba la exclusión de otros sectores políticos. Como bien resume Viera Gallo (2013): «La línea conductora era el reencuentro de la centroizquierda, pero servía de tribuna libre para quienes luchaban por la democracia.» Entonces, lo que comenzó como una iniciativa para reunir a la matriz cristiana que había estado en bandos diferentes en el gobierno de la UP, ante el contexto que estaba enfrentando Chile y su propia realidad marcada por el exilio, condujo al agrupamiento para luchar contra la dictadura y así recuperar juntos la democracia.

A medio año de la creación de Chile-América, la revista hacía un balance en el que concluía:

Estamos contentos de la acogida muy positiva que ha tenido nuestra publicación. Aspiramos a servir, además, como un lugar de encuentro, de análisis, al que puedan concurrir las diversas corrientes a fin de facilitar el diálogo, el conocimiento mutuo, y la búsqueda de todo aquello que permita sumar fuerzas ${ }^{13}$

Así, Chile-América se fue configurando como un espacio de encuentro, de sociabilidad en el exilio y, por supuesto, de difusión.

\section{Temas e intelectuales: los ejes centrales que articulaban el debate en Chile-América.}

El desarrollo narrativo de Chile-América cuenta con dos etapas temporales bien definidas y que se fueron diferenciando por cambios dentro de la estructuración y amplitud de la discusión política. En este sentido, los temas de los discursos se conservaron, pero se desarrollaron matices dentro de ellos, como veremos a continuación.

La primera etapa que podemos identificar fue desde 1974 a 1978, periodo en el cual se publicaron cuarenta y nueve revistas en total. En

${ }^{13}$ Chile-América, (1975), (6-7), p. 8. 
este primer periodo la revista se dividía por lo general en ocho apartados: 1) Editoriales, 2) Análisis y comentarios, 3) Elaboración teórica, análisis y debate en torno a la experiencia en Chile y a las perspectivas futuras, 4) Aspectos y problemas de la realidad chilena, 5) Problemas de la realidad latinoamericana e internacional, 6) Documentos, 7) Crónicas y 8) Notas breves.

Los temas desarrollados eran de gran diversidad, pero había un mayor número y extensión de ejes temáticos relacionados con el análisis y debate de la situación política de Chile, donde además se ponía especial atención al análisis y comentarios de noticias contingentes en el país. De esta manera podemos encontrar recortes de noticias y editoriales de revistas que se encontraban al interior de Chile. Como bien dice Moyano (2011), el énfasis en el análisis político contingente estaba orientado especialmente a rescatar e informar lo que estaba ocurriendo al interior del país: «nominar hacia otros espacios con el fin de disputar una narración informativa» (p. 39). Según podemos ver en el sumario temático que hace Chile-América también se destacaban en este espacio los análisis económicos y las entrevistas.Dentro de este gran eje temático entre 1974 y 1978 podemos distinguir los aportes de los siguientes intelectuales: Sergio Caballero, Esteban Tomic, Jaime Gazmuri, Rolando Ortega, Jaime Estévez.

El segundo eje temático que destaca por su número y extensión de desarrollo fue en torno a los debates teóricos y análisis ideológicos de las «fuerzas democráticas», en los que se acentúa una perspectiva desde el exterior o desde el exilio sobre los partidos políticos. Sobre estos temas escriben dirigentes o importantes personeros políticos, quienes el eurocomunismo, los debates socialdemócratas y las críticas al socialismo real. $\mathrm{Al}$ respecto, Moyano (2011) señala que la constitución de este eje temático se convirtió en un «espacio reflexivo transnacional», que tenía como elemento clave la «apropiación y relectura ideológica que muchos líderes chilenos de la renovación hicieron de la izquierda, socialismo y la democracia» (p. 39). Este espacio reflexivo se encontraba concentrado en dos apartados, denominados Análisis y Tribuna Abierta. Algunos de los intelectuales que escribieron en estas secciones entre 1974 a 1978 fueron: Raúl Ampuero, Jorge Arrate, Julio Silva Solar, Radomiro Tomic, Luis Razeto, Andrés Zaldívar, Aniceto Rodríguez y Clodomiro Almeyda, entre otros.

A lo anterior se añade un análisis crítico que realizó la izquierda al gobierno de la UP y la caracterización de la dictadura militar. Este fue un 
elemento importante de destacar, debido a que la misma revista encontraba necesario tener un espacio donde se hicieran reflexiones críticas acerca de la derrota ocurrida en 1973. En este apartado los intelectuales que escribieron fueron variados, pero nosotros destacamos los aportes de Jorge Arrate, ya que hizo su primera contribución desde una perspectiva «gramsciana» y en su segundo escrito fue sumamente duro en la autocrítica que hace a la izquierda chilena y las Fuerzas Armadas. Además, escribieron Raúl Ampuero, Clodomiro Almeyda, Sergio Bitar y Radomiro Tomic, entre muchos otros.

Un tercer eje fue el marcado por la discusión en torno al rol de la Iglesia en Chile y de la DC. En esta primera etapa podemos observar un marcado interés por informar y difundir lo que estaba haciendo el PDC a partir de anexos de documentación, noticias y análisis en torno al partido. En la temática de la Iglesia debe mencionarse la relación que existió entre la revista Chile-América y Mensaje. En varias oportunidades esta última fue utilizada como fuente de información de lo que estaba ocurriendo al interior de Chile.

El cuarto eje estructuraba los problemas de la realidad latinoamericana e internacional, con especial atención en la política latinoamericana de los Estados Unidos. Además, se analizaba el rol de la Iglesia en América Latina y el militarismo que azotaba a la región.

Por último, el quinto eje estaba relacionado con los Derechos $\mathrm{Hu}-$ manos, espacio que tenía una triple connotación: en primera instancia, informativa; también difusora de los horrores que se estaban cometiendo en Chile; y política, ya que se procuraba el descrédito en el extranjero de la dictadura de Pinochet. Además, se buscaba ayuda internacional, tanto monetaria como política en los vetos y censuras a Chile en distintas instancias supranacionales, como la Organización de Estados Americanos y la Organización de las Naciones Unidas. Podríamos agregar un cuarto elemento, de rescate de los testimonios de las mujeres y hombres que sobrevivieron a los centros de detención y tortura. Durante los casi diez años de existencia de la revista, siempre se publicó la sección de Derechos Humanos, además de innumerables dossiers sobre desaparecidos y presos, fallecidos, detenciones, desapariciones de menores, etc.

La segunda etapa que podemos ver en la revista es la marcada por las ediciones de 1979 a 1983. Aunque pueden visualizarse los mismos ejes temáticos que en la primera etapa, la diferencia con respecto a la primera radica en la importancia que adquirió como principal foco de atención el debate teórico y los problemas ideológicos de las fuerzas 
democráticas en torno a la renovación de los partidos de izquierda y su convergencia. En estos años colaboraron autores como: Rodrigo Baño, Claudio Orrego, Gabriel Valdés, Manuel Antonio Garretón,Eugenio Tironi, Sergio Bitar, Eduardo Novoa, Benjamín Teplizky, Tomás Moulian, Luis Corvalán y Patricio Aylwin entre otros. ${ }^{14}$

En estas ediciones pueden seguirse debates y problemáticas que tuvieron fuerte repercusión en Chile, tales como: la división del Partido Socialista, el movimiento de convergencia socialista, la imposibilidad de la «Revolución» apostando por el reformismo, la opción armada del PC en 1980, el análisis del papel de las Fuerzas Armadas en la política, etc. ${ }^{15}$ Además, Chile-América tuvo otro cambio: empezó a desarrollar temas relacionados con las mujeres. Mujeres empiezan hablar sobre feminismo, las mujeres exiliadas, la violencia dictatorial sobre la mujer, etc. En algunos números se estableció una sección denominada Presencia de la Mujer. Pero, sobre todo, en estos últimos años de edición vemos la creación de un apartado exclusivo sobre la cultura o la vida cultural, lo que marcó un cambio importante en Chile-América.

Aunque no dejó de ser una revista estructurada predominantemente a través de un contenido de análisis político, estas nuevas publicaciones abrieron debates concernientes no solo a la política de partidos políticos, sino a lo político, donde el campo cultural podía ser una herramienta de análisis para la lucha democrática. Además, empezaron a agregarse noticias culturales variadas, por lo general de actividades y trabajos generados en el exilio.

En consecuencia, en casi diez años de vida Chile-América publicó ochenta y nueve números a través de los cuales se convirtió en un espacio donde convergían las noticias del interior y las relecturas y debates que se daban en el exterior.

\section{La problemática de la difusión: ¿Dónde se leía Chile-América?}

Aunque no tenemos datos exactos, sabemos que en enero de 1978 la revista anunciaba con satisfacción que la campaña de 1000 suscripto-

\footnotetext{
${ }^{14}$ Es importante precisar que varios de estos intelectuales escribieron en ambos periodos de la revista, lo cual se entiende porque Chile-América no sufrió un cambio sustantivo en sus temáticas.

${ }^{15}$ Chile-América, (julio-agosto-septiembre de 1982), (80), pp. 53-88.
} 
res había tenido una respuesta auspiciosa y que en un año habían podido triplicar el número de suscriptores, pero que aún faltaba mucho para alcanzar la meta trazada. Además informaba que para ese entonces Chile-América había logrado ampliar su difusión y que a esa fecha contaba con suscriptores en países de América, Europa, Oceanía, Asia y África. ${ }^{16}$

Aunque no fuera fácil hacerlo, Chile-América ingresaba periódicamente al país, lo cual puede comprobarse a partir de las cartas que empezaron a publicarse a partir del segundo número de la revista. En la sección Nos escriben y opinan escribían dos chilenos residentes en el país: Gabriel Díaz de Santiago y Juan Bautista Riquelme de Valparaíso. Junto con las cartas enviadas por los chilenos, se encontraba otras de: N. Gómez de Caracas, Venezuela; Pat Hocking, de San Francisco, Estados Unidos; Nestor Chávez, de Lima, Perú; Jacinto Marchiotti de Buenos Aires, Argentina; y Carlos Guerrero, de Roma, Italia. ${ }^{17}$

Nos escriben y opinan se mantuvo durante toda la existencia de la revista, en ella se recogían, a través de las cartas enviadas, diversas opiniones y permite constatar si realmente la revista llegaba a los países que Chile-América establecía como suscriptores, pero, más importante, posibilita dilucidar a qué lugares de Chile llegaba la revista. La misma revista nos proporciona información acerca de sus suscriptores en 1977, estableciendo que estos se distribuían de la siguiente forma: Venezuela, 20\%; Francia, 16\%; Estados Unidos, 14\%; República Federal Alemana (RDA), 7\%; Inglaterra, 5\%; Canadá, Costa Rica y España, 4\% cada uno; Suiza, 3\%; Suecia, 2\%. El otro 22\% de los suscriptores se distribuían entre América Latina, África, Europa, países socialistas, Asia y Oceanía. Además, se añadía que México, Colombia y Brasil son países donde les iba muy mal. ${ }^{18}$

Esta información concuerda parcialmente con el análisis cualitativo y cuantitativo realizado a las cartas al director. En las 89 publicaciones de Chile-América, solo la primera edición no contó con la sección Nos escriben y opinan.

\footnotetext{
${ }^{16}$ Argentina, Bolivia, Brasil, Canadá, Colombia, Costa Rica, Cuba, Ecuador, Estados Unidos, Guatemala, Guayana, Honduras, México, Panamá, Perú, Uruguay, Venezuela y también Chile; Alemania Federal, Alemania Democrática, Austria, Bélgica, Dinamarca, Escocia, España, Finlandia, Francia, Holanda, Inglaterra, Italia, Luxemburgo, Noruega, Portugal, Suecia, Polonia, Unión Soviética y Yugoslavia. Además, en Argelia, Australia, Guinea Bissau, India, Indonesia, Israel, Japón, Kenya, Mali, Mozambique y República Popular del Congo. Chile-América, (enero-febrero-marzo de 1978), (39-40), p.12.

${ }_{17}$ Chile-América, N², octubre 1974, p. 2.

${ }^{18}$ Chile-América, (mayo-junio de 1977), (31-32), p. 6.
} 
Cuadro 1: Total de Cartas enviadas desde el extranjero 19741983, Chile-América ${ }^{19}$

\begin{tabular}{|c|c|c|}
\hline País & $\begin{array}{l}\text { Número de Cartas enviadas } \\
\text { desde el extranjero 1974-1983 }\end{array}$ & Porcentajes \\
\hline Venezuela & 25 & $11 \%$ \\
\hline EE.UU & 32 & $14 \%$ \\
\hline Perú & 7 & $3 \%$ \\
\hline Italia & 32 & $14 \%$ \\
\hline Argentina & 3 & $1 \%$ \\
\hline Australia & 3 & $1 \%$ \\
\hline RFA & 16 & $7 \%$ \\
\hline Inglaterra & 15 & $7 \%$ \\
\hline México & 7 & $3 \%$ \\
\hline RDA & 6 & $3 \%$ \\
\hline Noruega & 5 & $2 \%$ \\
\hline Bélgica & 6 & $3 \%$ \\
\hline Holanda & 3 & $1 \%$ \\
\hline Francia & 21 & $10 \%$ \\
\hline España & 9 & $4 \%$ \\
\hline Colombia & 3 & $1 \%$ \\
\hline Mozambique & 2 & $1 \%$ \\
\hline Costa Rica & 4 & $2 \%$ \\
\hline Yugoslavia & 2 & $1 \%$ \\
\hline Ecuador & 3 & $1 \%$ \\
\hline Suecia & 2 & $1 \%$ \\
\hline Otros $^{*}$ & 15 & $7 \%$ \\
\hline TOTAL & 221 & 100 \\
\hline
\end{tabular}

*Portugal, Brasil, Bolivia, Argelia, Escocia, Guatemala, Uruguay, Austria, Finlandia, Surinam, Suiza, URSS, Panamá, Berlín (sin especificación) y Nicaragua.

Fuente: Elaboración propia.

${ }^{19}$ Aunque se revisó casi la totalidad de las revistas, no se tuvo acceso a Chile-América, (8-9), (12-13), (37-38), (43-47). 
De estas cifras podemos concluir que los lugares que realizaron más aportes de cartas al director fueron aquellos donde había mayor cantidad de exiliados chilenos. En efecto, aunque algunos porcentajes variaron desde 1977 a 1983, se mantuvo fuerte la tendencia de aportes de Estados Unidos, Venezuela, Francia, República Federal Alemana e Inglaterra.

Ahora bien, ¿Chile-América se leía en Chile? Como dijimos anteriormente no contamos con cifras exactas, pero haciendo el mismo análisis de las cartas dirigidas al director podemos establecer los lugares de donde provenían las cartas y por lo tanto, las zonas a donde llegó la revista.

Cuadro 2: Total de Cartas enviadas desde Chile 1974-1983, Chile-América

\begin{tabular}{|l|c|c|}
\hline Ciudad & $\begin{array}{c}\text { Número de Cartas } \\
\text { enviadas desde Chile 1974-1983 }\end{array}$ & Porcentajes \\
\hline Santiago & 133 & $71 \%$ \\
Valparaíso & 14 & $7 \%$ \\
Viña del Mar & 11 & $6 \%$ \\
Linares & 2 & $1 \%$ \\
Concepción & 7 & $4 \%$ \\
Antofagasta & 2 & $1 \%$ \\
Curicó & 2 & $9 \%$ \\
Otros* & 16 & 100 \\
\hline TOTAL & 187 & \\
\hline
\end{tabular}

*Punta Arenas, Parral, Zapallar, Talca, Pirque, Talagante, Quillota, Rancagua y Valdivia.

Fuente: Elaboración propia

De acuerdo a estos datos, podemos establecer que el principal aporte de cartas al director provenían de Santiago y de la zona centro-sur del país. Además, en estas cartas podemos no solo leer las opiniones de hombres y mujeres acerca de temas contingentes en Chile y el mundo, sino que también observamos que la revista llega periódicamente a ciertas personas y organizaciones, pese a la censura impuesta por el régimen. En consecuencia, por medio de la información presentada pode- 
mos señalar que la Revista Chile-América fue leída tanto en Chile, como en el extranjero, llegando a abarcar su distribución a casi 40 países.

\section{Comentarios finales}

Cuatro son las conclusiones preliminares que podemos sacar de la investigación desarrollada. En primer lugar, la revista estudiada se convirtió en un mecanismo de conexión y vinculación con los exiliados chilenos, a través de la cual se buscó disminuir la sensación de aislamiento. Asimismo, sirvió como medio de circulación de ideas y debates tanto en el interior de Chile, como en el exterior. Bajo estas características, la revista asumió un papel de resistencia cultural y política contra los regímenes autoritarios, actuando desde el exilio como espacio organizado de oposición política.

En segundo lugar, el análisis de Chile-América nos permite encontrar un lugar común donde podemos observar el movimiento de las ideas, conflictos y proyectos que se fueron gestando en el exilio. Además de concebirla como un espacio de sociabilidad y un actor político-cultural, la revista fue estimulando la unidad de ciertas expresiones políticas, en redes de sociabilidad intelectual, que se materializaron en las discusiones narrativas que, sin tener las mismas raíces políticas, elaboraron propuestas comunes.

En tercer lugar, Chile-América contribuyó a la formación de redes de sociabilidad transnacionales, buscando conectar a intelectuales que vivieran tanto en Chile como en el exterior y así pensar en políticas alternativas a la dictadura militar chilena y aquellas que azotaban al Cono Sur. Por lo tanto, no es de extrañar que el mayor número de editoriales fueran condenatorias al régimen de Pinochet y al militarismo latinoamericano y que al mismo tiempo buscaran una salida a la dictadura. Asimismo, esgrimían críticas a la política neoliberal, proponían nuevos caminos políticos y denunciaban las violaciones a los derechos humanos.

En cuarto lugar, Chile-América dio cuenta de un discurso programático, que tenía como base el ideario de los creadores y posteriormente integrantes del Consejo Editor, opiniones y postulados que no solo se presentaban en la sección editorial, sino también en la paginación, artículos, dossiers, notas, crónicas de derechos humanos y, en general, en todos los textos que articulaban la revista. 
Aunque la revista tuvo que enfrentar múltiples problemas, se siguió editando, logrando estar en contacto con el mundo y con Chile por casi diez años. En la edición de julio-octubre de 1983 se notificaba el cese de la publicación por dos motivos. Por una parte, las vicisitudes económicas y, por otra, los miembros del Consejo de Chile-América fueron autorizados a regresar a Chile. Sin embargo, el Centro de Estudio y Documentación seguiría funcionando bajo su supervisión. ${ }^{20}$

\section{Referencias}

Alburquerque, G. (2011). La trinchera letrada. Intelectuales latinoamericanos y Guerra Fría. Santiago: Ariadna Ediciones..

Arrate, J. y Rojas, E. (2003). Memoria de la izquierda chilena, Tomo II, (1979-2000). Santiago: Ediciones Chile S.A.

Brinkmann, B. (1999). Itinerario de la Impunidad. Chile 1973-1999. Santiago: CINTRAS.

Corvalán, L. (2016). Los partidos politicos y el golpe del 11 de septiembre. Contribución al estudio del contexto histórico. Santiago: Editorial Universidad de Santiago.

Dorat, C. y Weibel, M. (2012). Asociación ilicita. Los archivos secretos de la dictadura. Santiago: Ceibo Ediciones.

García, Y. (2013). El trabajo militante del exilio chileno en Francia: Contextualización, descripción, micro-medios de comunicación y sus impactos. Revistas Izquierdas (17), 81-92.

Gilman, C. (2012). Entre la pluma y el fusil. Debates y dilemas del escrito revolucionario en América Latina. Buenos Aires: Siglo Veintiuno Editores.

Moyano, C. (2011). Diálogos entre el exilio y el interior. Reflexiones en torno a la circulación de ideas en el proceso de renovación socialista, 1973-1990. Revista Izquierdas, (9), 31-46.

Norambuena, C. (2000). Exilio y retorno. Chile. 1973-1994. En M. Garcés et al (Comp.). Memorias para un nuevo siglo. Chile, miradas a la segunda mitad del siglo $X X$. Santiago: Lom Ediciones.

\footnotetext{
${ }^{20}$ Chile-América, (julio-agosto-septiembre-octubre de 1983), (88-89).
} 
Rebolledo, L. (2006). Memorias del desarraigo. Testimonios de exilio y retorno de hombres y mujeres de Chile. Santiago: Catalonia.

Salazar, M. (2011). Las letras del horror. Tomo I: La DINA. Santiago: Lom Ediciones.

Salazar, M. (2012). Las letras del horror. Tomo II: La CNI. Santiago: Lom Ediciones.

Tomic, E. (2013). Chile-América: un salto en el vacío. Disponible en: http://www.cedocmuseodelamemoria.cl/wp-content/uploads/2013/ 01/palabra-tomicl.pdf

Viera-Gallo, J. (2013). El Compromiso. Santiago: Aguilar Chilena de Ediciones. 